\title{
Increased incidence of invasive group A streptococcal infections in Sweden, January 2012-February 2013
}

J Darenberg (Jessica.Darenberg@smi.se) ${ }^{1}$, B Henriques-Normark ${ }^{1,2,3}$, T Lepp ${ }^{1}$, K Tegmark-Wisell ${ }^{1}$, A Tegnell ${ }^{1}$, K Widgren ${ }^{1}$

1. Swedish Institute for Communicable Disease Control (SMI), Solna, Sweden

2. Department of Microbiology, Tumor and Cell Biology, Karolinska Institutet, Stockholm, Sweden

3. Department of Laboratory Medicine, Division of Clinical Microbiology, Karolinska University Hospital, Stockholm, Sweden

Citation style for this article:

Darenberg J, Henriques-Normark B, Lepp T, Tegmark-Wisell K, Tegnell A, Widgren K. Increased incidence of invasive group A streptococcal infections in Sweden, January 2012-February 2013. Euro Surveill. 2013;18(14):pii=20443. Available online: http://www.eurosurveillance.org/ViewArticle.aspx?Articleld=20443

Article submitted on 20 March 2013 / published on 04 April 2013

The incidence of invasive group A streptococcal infections in Sweden was 6.1 per 100,000 population in 2012, the highest since the disease became notifiable in 2004. Furthermore, January and February 2013 marked a dramatic increase of cases notified, partly explainable by an increase of emm1/ $\mathrm{T}_{1}$ isolates, a type previously shown to cause severe invasive disease more often than other types. Healthcare providers in Sweden and health authorities in neighbouring countries have been informed about this increase.

\section{Background}

Group A streptococci (GAS) can cause a variety of diseases, ranging from mild or moderate infections, such as tonsillitis and erysipelas, to more severe and sometimes life threatening conditions with septicaemia, shock and/or necrotizing fasciitis [1]. Furthermore, many individuals are asymptomatic carriers of GAS, especially children. Analyses have shown that $12 \%$ of children older than five years are carriers, as compared to $4 \%$ among younger children [2].

The number of invasive group A streptococcal (iGAS) infections often has a seasonal pattern with peaks during the winter and spring months. Furthermore, variations in the yearly number of reported cases are not uncommon. The cause of these variations is not fully known, but is likely dependent on factors such as underlying co-existing medical conditions, seasonal influenza infections, the GAS types that are circulating in the community, and the immunity against these types in the population. The prevalence of specific GAS types in a community shows high variability depending on geographic area and time period studied [3-6].

Invasive infection with GAS is notifiable in Sweden, according to the Communicable Diseases Act, since 1 July 2004 . Both the physician at the diagnosing laboratory and the treating physician are obliged by this law to report iGAS cases to the county medical officer and to the Swedish Institute for Communicable Disease Control (SMI). Invasive isolates are normally collected in Sweden at national level at least every fifth year.
Due to the noted increase of reported cases in 2012, we started collecting isolates ahead of time.

Here, we report an increased number of notified cases of severe GAS infection in Sweden, with a predominance of type emm1/T1 during 2012, and a further increase during the first two months of 2013.

\section{Clinical data collection}

Demographic information on iGAS cases were analysed using data from notification forms collected in the national surveillance database SmiNet. In order to establish the date of death, if applicable, the notification forms were linked to the national death register, using the personal identification code of each individual. Additionally, we calculated case-fatality rate for deaths within seven days from bacterial sampling.

\section{Epidemiological typing}

Available iGAS isolates ( $85 \%$ of all reported cases) from the clinical microbiological laboratories in Sweden were collected during 2012 and characterised by serological T-typing $(n=400)$ and sequence-based emm typing ( $n=494$ in 2012, and $n=113$ in 2013). The T-typing was performed using poly- and monospecific $T$ antisera (Sevapharma). Genomic DNA was prepared from the isolates, and the emm-types determined by direct sequencing of PCR-products covering the $\mathrm{N}$-terminal hypervariable portion of the emm gene [7].

\section{Statistics}

Incidence was calculated using population data as of 1 November each year from Statistics Sweden. The incidence in 2012 was compared to the incidence of each of the preceding years between 2006 and 2011, and we calculated the mean of the differences in incidence and the mean of the incidence rate ratios. A one-sample two-sided t-test was then applied to test the null hypothesis that the incidence was the same in 2012 as in previous years. Data from 2004 and 2005 were excluded as there could have been suboptimal completeness in the first few years of the notification system. Differences in type distribution between 2012 


\section{FIGURE 1}

Reported cases of invasive group A streptococcal infections per month, Sweden, January 2007-February 2013

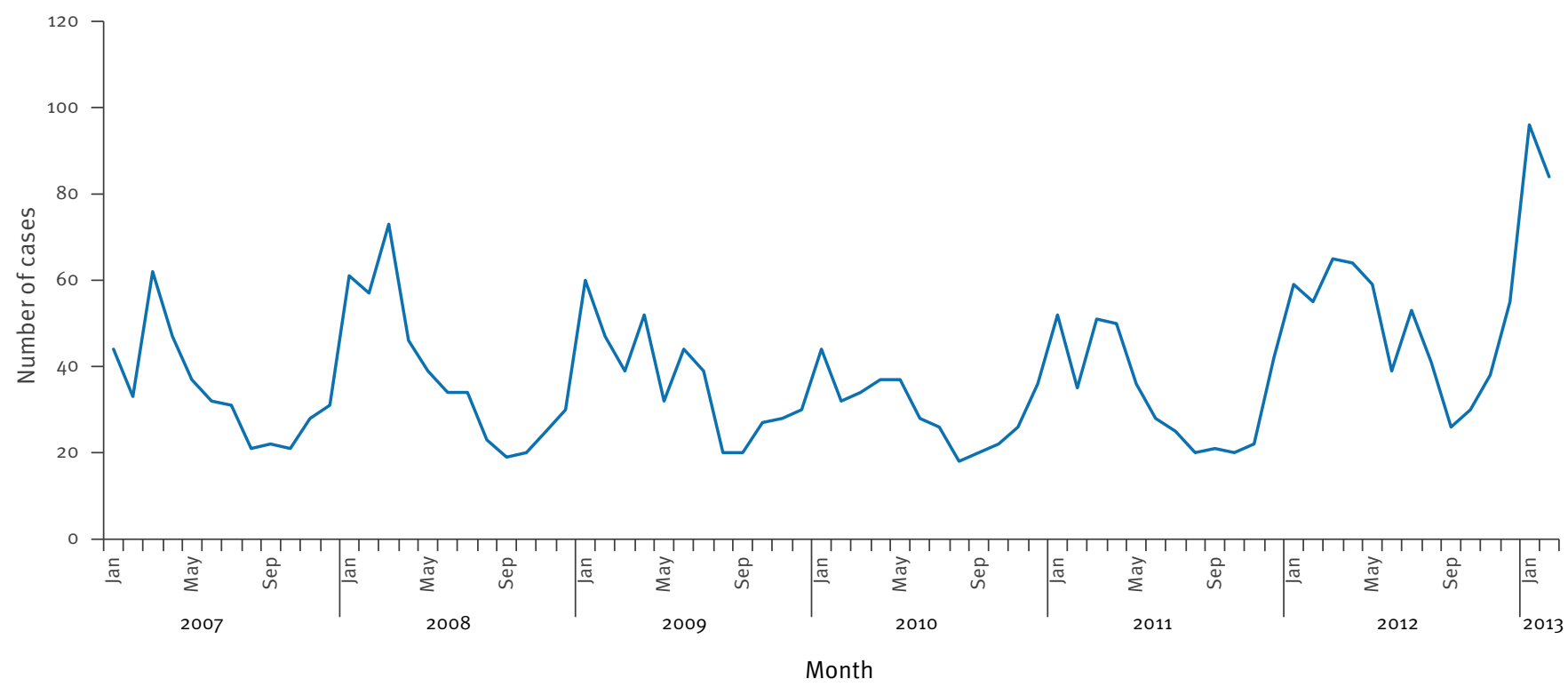

\section{TABLE}

Number of cases of invasive group A streptococcal infections and incidence per 100,000 inhabitants, Sweden, 2006-2012

\begin{tabular}{|c|c|c|c|c|c|c|c|c|c|c|}
\hline \multirow{2}{*}{ Age group (years) } & 2006 & 2007 & 2008 & 2009 & 2010 & 2011 & 2012 & \multirow{2}{*}{$\begin{array}{l}\text { Mean incidence } \\
2006-2011\end{array}$} & \multirow{2}{*}{$\begin{array}{l}\text { Difference in } \\
\text { incidence } \\
(95 \% \mathrm{Cl})^{\mathrm{a}}\end{array}$} & \multirow{2}{*}{$\begin{array}{c}\text { Incidence rate } \\
\text { ratio } \\
(95 \% \mathrm{Cl})^{\mathrm{a}}\end{array}$} \\
\hline & \multicolumn{7}{|c|}{ Number of cases (incidence) } & & & \\
\hline $0-19$ & $\begin{array}{c}25 \\
(1.2) \\
\end{array}$ & $\begin{array}{c}40 \\
(1.9) \\
\end{array}$ & $\begin{array}{c}31 \\
(1.4) \\
\end{array}$ & $\begin{array}{c}30 \\
(1.4) \\
\end{array}$ & $\begin{array}{c}17 \\
(0.8) \\
\end{array}$ & $\begin{array}{c}33 \\
(1.5) \\
\end{array}$ & $\begin{array}{c}45 \\
(2.1) \\
\end{array}$ & 1.4 & $\begin{array}{c}0.73 \\
(0.35-1.11) \\
\end{array}$ & $\begin{array}{c}1.65 \\
(1.09-2.22) \\
\end{array}$ \\
\hline $20-39$ & $\begin{array}{c}42 \\
(1.8) \\
\end{array}$ & $\begin{array}{c}58 \\
(2.5) \\
\end{array}$ & $\begin{array}{c}60 \\
(2.6) \\
\end{array}$ & $\begin{array}{c}60 \\
(2.5) \\
\end{array}$ & $\begin{array}{c}8 \\
(1.6) \\
\end{array}$ & $\begin{array}{c}58 \\
(2.4)\end{array}$ & $\begin{array}{c}69 \\
(2.8) \\
\end{array}$ & 2.2 & $\begin{array}{c}0.57 \\
(0.12-1.01) \\
\end{array}$ & $\begin{array}{c}1.30 \\
(1.00-1.60) \\
\end{array}$ \\
\hline $40-59$ & $\begin{array}{c}79 \\
(3.2) \\
\end{array}$ & $\begin{array}{c}85 \\
(3.5) \\
\end{array}$ & $\begin{array}{c}95 \\
(3.9) \\
\end{array}$ & $\begin{array}{c}91 \\
(3.7) \\
\end{array}$ & $\begin{array}{c}78 \\
(3.2) \\
\end{array}$ & $\begin{array}{c}77 \\
(3.1) \\
\end{array}$ & $\begin{array}{c}116 \\
(4.7) \\
\end{array}$ & 3.4 & $\begin{array}{c}1.23 \\
(0.90-1.56) \\
\end{array}$ & $\begin{array}{c}1.37 \\
(1.24-1.49) \\
\end{array}$ \\
\hline $60-79$ & $\begin{array}{c}110 \\
(6.5)\end{array}$ & $\begin{array}{c}137 \\
(7.9)\end{array}$ & $\begin{array}{c}157 \\
(8.8)\end{array}$ & $\begin{array}{c}156 \\
(8.5) \\
\end{array}$ & $\begin{array}{c}129 \\
(6.9)\end{array}$ & $\begin{array}{c}118 \\
(6.2)\end{array}$ & $\begin{array}{c}218 \\
(11.4)\end{array}$ & 7.5 & $\begin{array}{c}3.89 \\
(2.76-5.02) \\
\end{array}$ & $\begin{array}{c}1.55 \\
(1.31-1.78) \\
\end{array}$ \\
\hline$\geq 80$ & $\begin{array}{c}67 \\
(13.4) \\
\end{array}$ & $\begin{array}{c}89 \\
(17.8) \\
\end{array}$ & $\begin{array}{c}118 \\
(23.5) \\
\end{array}$ & $\begin{array}{c}101 \\
(20.1) \\
\end{array}$ & $\begin{array}{c}98 \\
(19.3) \\
\end{array}$ & $\begin{array}{c}116 \\
(22.9) \\
\end{array}$ & $\begin{array}{c}136 \\
(26.8) \\
\end{array}$ & 19.5 & $\begin{array}{c}7.30 \\
(3.45-11.15) \\
\end{array}$ & $\begin{array}{c}1.42 \\
(1.09-1.75) \\
\end{array}$ \\
\hline Total & $\begin{array}{r}323 \\
(3.5) \\
\end{array}$ & $\begin{array}{l}409 \\
(4.5)\end{array}$ & $\begin{array}{r}461 \\
(5.0) \\
\end{array}$ & $\begin{array}{l}438 \\
(4.7)\end{array}$ & $\begin{array}{r}360 \\
(3.8)\end{array}$ & $\begin{array}{l}402 \\
(4.2)\end{array}$ & $\begin{array}{l}584 \\
(6.1) \\
\end{array}$ & & & \\
\hline
\end{tabular}

$\mathrm{Cl}$ : confidence interval.

a Comparisons of the incidence in 2012 with the mean incidence 2006-2011. 
and the first months of 2013 were tested using the chisquare test. The alpha error was set to 0.05 .

\section{Results}

In 2012,584 cases of iGAS infections were notified in Sweden which corresponds to an annual incidence of 6.1 cases per 100,000 inhabitants. This is the highest yearly number and incidence of reported cases since these infections became notifiable in 2004 (Figure 1). Furthermore, in January and February 2013, an additional 96 and 84 cases respectively were reported, which indicates a continuing increase in incidence rate also during 2013 (Figure 1).

The median age of the cases in 2012 was 65 years and the highest incidence was seen among people above 80 years of age. Men and women were equally affected, except for the age group 20-39 years where women were overrepresented. Of 43 women in this age group, $30 \%$ had confirmed puerperal sepsis. In total, $60 \%$ of these women had gynaecological infections.

The incidence rate ratio was significantly higher in 2012 compared to previous years, in all age groups except for a borderline difference for the 20-39 years age group (Table). However, the difference in incidence was the highest in the age group 80 years and above (an increase of 7.3 cases per 100,000 inhabitants per year).

In 2012,46 of the 584 cases ( $8 \%$ ) died within seven days from bacterial culture sampling. This is comparable with Swedish data from 2010-2011 (data not shown). The median age for deceased patients was 77 years.

So far 400 (68\%) isolates from the reported cases in 2012 have been received for T- and emm-typing. In addition, 94 isolates have been emm-typed only. Overall, $30 \%$ of the typed 494 isolates were emm1/ $\mathrm{T}_{1}$ in 2012, followed by emm-types 89 (15\%) 28 (14\%) and $3(11 \%)$ (Figure 2$)$. However, preliminary data from isolates sampled during the first two months 2013 shows a significant increase of emm1/ $\mathrm{T}_{1}$ constituting about $55 \%$ of the 113 typed isolates (p<0.001) (Figure 3). Bacterial isolates from 39 of the 46 deceased patients in 2012 have been received for typing; 13 of the isolates were emm1, followed by $7 \mathrm{emm} 3$ and $6 \mathrm{emm} 89$. The type distribution for these patients cannot be compared to previous years, as isolates were not collected for typing then.

\section{Discussion}

In 2012 we observed the highest yearly number of notified cases of invasive GAS infections since it became notifiable in Sweden 2004. January 2013 marked the highest number of cases reported in a single month so far, continuing also during February. Importantly, we noticed an emergence of emm1/ $\mathrm{T}_{1}$ among these invasive cases. The relative increase in incidence in 2012 compared to previous years was similar for all age
FIGURE 2

Type distribution of invasive group A streptococcal isolates sampled in 2012, Sweden

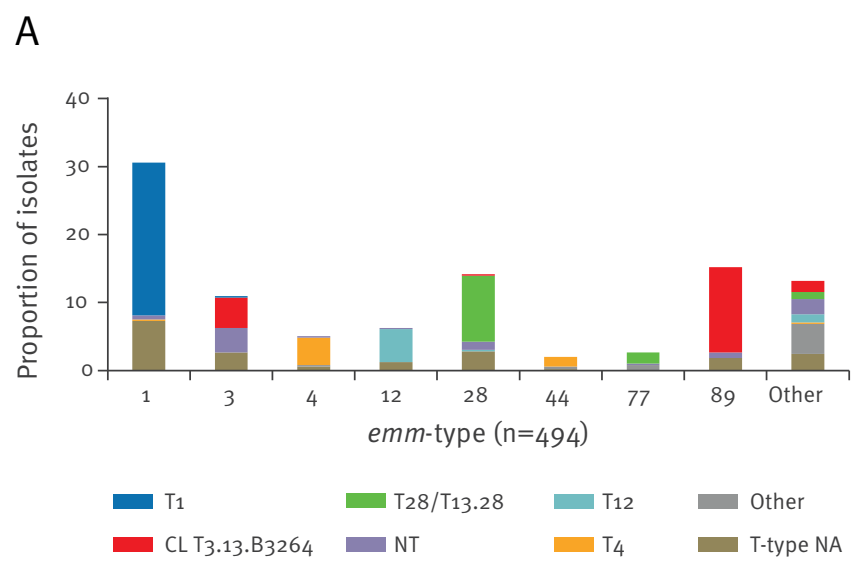

B

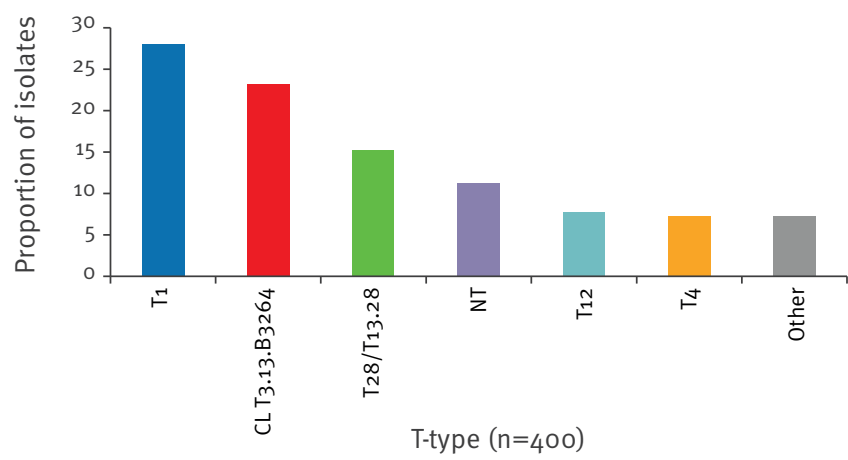

CL: cluster (consists of different combinations of T3.13.B3264).

groups. However, as the incidence was highest among the elderly ( 80 years and above) the largest increase in absolute numbers was seen within this group. A similar increase in the number of cases has not been seen in our neighbouring countries during 2012. However, Finland noted a somewhat increased incidence in 2012 as compared to 2011 (4.4 cases per 100,000 population in 2012, compared to 3.13 cases per 100,000 population in 2011). Furthermore, an increase has been noted in Norway during the first months of 2013 as compared to the same time period last year, with twice as many reported cases. So far, 60 cases have been reported in Norway in 2013 and 56 have been typed; $24 \%$ of the isolates typed are emm1 (personal communications, S Hoffmann (SSI, Denmark), J Voupio-Varkila (THL, Finland), M Steinbakk (FHI, Norway), March-April 2013). Several reasons can be suggested to explain this increase in incidence in Sweden. Raised awareness in local authorities and laboratories, who had been informed in spring 2012, may partly explain this increase. Also an increased transmission of respiratory 


\section{FIGURE 3}

Reported cases of invasive group A streptococcal infection per month and proportion of emm sequenced isolates, including the three most prevalent $\mathrm{emm}$-types, Sweden, 2012-2013

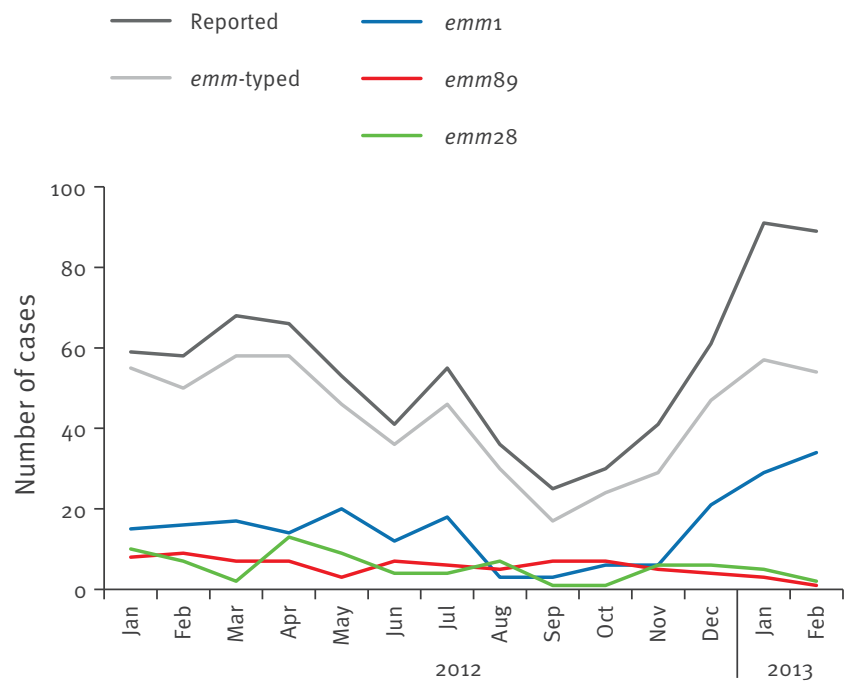

Sample month

viral diseases could potentially be a factor, since GAS infections can be transmitted secondary to these infections, especially influenza virus infection $[8,9]$. An increase of viral infections, not only the seasonal influenza, has been noted in Sweden during the present season. The increase of iGAS infection was first noted during the spring months of 2012, with the prevalence remaining high in autumn 2012, before the influenza season started.

A correlation has previously been found between certain $e m m$-types and disease. The emm1/ $\mathrm{T}_{1}$ type has been shown to cause more severe infections, often with higher fatality rates than other serotypes and was, together with type emm3 isolates, the predominant cause of outbreaks of severe iGAS disease during the 1980s, also in Sweden [10-12]. Interestingly, the type distribution among the isolates in our surveillance study from 2002 to 2004 showed a completely different type distribution as compared to the present study. During that time period, emm-types 89 and 81 accounted for $30 \%$ of the isolates and emm 1 for $12 \%$ only [13]. Furthermore, emm3 isolates were very scarce, as compared to $11 \%$ of the isolates typed in 2012 . In 2009 we performed another survey of iGAS infection where $83 \%$ of the reported isolates were T-typed. The type distribution was more similar to the present study, as the major types in descending order then were $\mathrm{T}_{1}(27 \%), \mathrm{T}_{2} 8(21 \%)$, those in the cluster $\mathrm{T}_{3} .13$. B3264 (20\%), NT (11\%) and 12 (7\%) (unpublished data). The present study, with the collection of bacterial isolates, makes it possible to characterise and study specific groups of isolates, such as the emm $1 / \mathrm{T}_{1}$, more in-depth in the future, and also to compare these with isolates collected during previous study periods.

The epidemiology of GAS disease changes over time, but also between countries. In a European Unionfunded collaboration, with 13 participating countries, differences in incidence and fatality rates were found between the countries which could be explained partly by differences in circulating types $[4,14]$. Only in a few European countries iGAS is a notifiable disease. However, we would recommend countries to monitor the national incidence of the disease, and that each country has alert systems to detect and analyse epidemiological changes.

Due to the observed increase of iGAS incidence in Sweden, SMI now informs healthcare providers through different channels about the emergence of these infections. The main purpose has been to create increased awareness of the disease to improve management and thereby possibly reduce mortality. Neighbouring countries have been contacted and informed of the situation in Sweden in order to increase awareness among healthcare providers in these countries.

SMI also encourages the laboratories to send clinical isolates for typing and will improve the collection of clinical data within the surveillance system in order to gain a better understanding of the epidemiology and transmission patterns of iGAS disease.

\section{Acknowledgements}

We thank the microbiological laboratories in Sweden for reporting cases and sending isolates for typing. We would also like to thank Ingrid Andersson and Christina Johansson for excellent technical assistance as well as Ann Cathrine Petersson, at the Clinical microbiology, University and regional laboratories Region Skåne for providing typing data from Skåne. In addition we would like to thank Jakob Bergström for statistical support. The work was supported by funds from Swedish Institute for Communicable Disease Control.

Authors' contribution

Jessica Darenberg, Tiia Lepp and Katarina Widgren performed the analyses and drafted the report. All authors supported the analysis, wrote the manuscript and approved the final report submitted. Anders Tegnell has an overall responsibility for the Swedish surveillance system that found the signal. Birgitta Henriques-Normark has the overall responsibility for the epidemiological typing.

Conflict of interest

None declared. 


\section{References}

1. Steer AC, Lamagni T, Curtis N, Carapetis JR. Invasive group a streptococcal disease: epidemiology, pathogenesis and management. Drugs. 2012;72(9):1213-27. http://dx.doi. org/10.2165/11634180-000000000-00000. PMid:22686614.

2. Shaikh N, Leonard E, Martin JM. Prevalence of streptococcal pharyngitis and streptococcal carriage in children: a metaanalysis. Pediatrics. 2010;126(3):e557-64. http://dx.doi. org/10.1542/peds.2009-2648. PMid:20696723.

3. Kaplan EL, Wotton JT, Johnson DR. Dynamic epidemiology of group A streptococcal serotypes associated with pharyngitis. Lancet. 2001;358(9290):1334-7. http://dx.doi.org/10.1016/ S0140-6736(01)06415-7.

4. Luca-Harari B, Darenberg I, Neal S, Siljander T, Strakova L, Tanna A, et al. Clinical and microbiological characteristics of severe Streptococcus pyogenes disease in Europe. J Clin Microbiol. 2009;47(4):1155-65. http://dx.doi.org/10.1128/ JCM.02155-08. PMid:19158266. PMCid:2668334.

5. Martin JM, Green M, Barbadora KA, Wald ER. Group A streptococci among school-aged children: clinical characteristics and the carrier state. Pediatrics. 2004;114(5):1212-9. http://dx.doi.org/10.1542/peds.20040133. PMid:15520098.

6. O’Brien KL, Beall B, Barrett NL, Cieslak PR, Reingold A, Farley $M M$, et al. Epidemiology of invasive group a streptococcus disease in the United States, 1995-1999. Clin Infect Dis. 2002; 35(3):268-76. http://dx.doi.org/10.1086/341409. PMid:12115092.

7. Beall B, Facklam R, Thompson T. Sequencing emm-specific PCR products for routine and accurate typing of group $A$ streptococci. J Clin Microbiol. 1996.34(4):953-8.

8. Chertow DS, Memoli MJ. Bacterial coinfection in influenza: a grand rounds review. JAMA; 2013;309(3):275-82. http://dx.doi. org/10.1001/jama.2012.194139. PMid:23321766.

9. McCullers JA. Planning for an influenza pandemic: thinking beyond the virus. J Infect Dis. 2008;198(7):945-7. http://dx.doi. org/10.1086/592165. PMid:18710326. PMCid:2548323.

10. Kaplan EL. The resurgence of group A streptococcal infections and their sequelae. Eur J Clin Microbiol Infect Dis. 1991;10(2):55-7. http://dx.doi.org/10.1007/BF01964407. PMid:1864275.

11. Strömberg A, Romanus V, Burman LG. Outbreak of group A streptococcal bacteremia in Sweden: an epidemiological and clinical study. J Infect Dis. 1991;164(3):595-8. http://dx.doi. org/10.1093/infdis/164.3.595. PMid:1869845.

12. Efstratiou A. Group A streptococci in the 1990s. J Antimicrob Chemother. 2000;45 Suppl: 3-12. http://dx.doi.org/10.1093/ jac/45.suppl_1.3. PMid:10759357.

13. Darenberg J, Luca-Harari B, Jasir A, Sandgren A, Pettersson $H$, Schalén C, et al. Molecular and clinical characteristics of invasive group A streptococcal infection in Sweden. Clin Infect Dis. 2007;45(4):450-8. http://dx.doi.org/10.1086/519936. PMid:17638193.

14. Lamagni TL, Darenberg J, Luca-Harari B, Siljander T, Efstratiou A, Henriques-Normark B, et al. Epidemiology of severe Streptococcus pyogenes disease in Europe. J Clin Microbiol. 2008;46(7): 2359-67. http://dx.doi.org/10.1128/JCM.00422-08. PMid:18463210. PMCid:2446932. 